\title{
Patient behaviour at the time of stroke onset: a cross-sectional survey of patient response to stroke symptoms
}

\author{
L Mellon, ${ }^{1,2}$ F Doyle, ${ }^{1}$ D Williams, ${ }^{2}$ L Brewer, ${ }^{2}$ P Hall, ${ }^{2}$ A Hickey ${ }^{1}$
}

'Department of Psychology, Royal College of Surgeons in Ireland, Dublin, Ireland ${ }^{2}$ Department of Geriatric and Stroke Medicine, Royal College of Surgeons in Ireland, Dublin, Ireland

\section{Correspondence to} Dr Lisa Mellon, Division of Population Health Sciences, Department of Psychology, Royal College of Surgeons in Ireland, Dublin 2, Ireland; lisamellon@rcsi.ie

Received 10 March 2015 Revised 21 December 2015 Accepted 22 December 2015 Published Online First 18 January 2016

\section{ABSTRACT \\ Background and purpose Revascularisation}

treatment with thrombolysis must be initiated within $4.5 \mathrm{~h}$ following ischaemic stroke symptom onset. Despite its proven benefits, thrombolysis therapy is underused, with patient delay in presenting to hospital with symptoms identified as the leading barrier. This study aimed to examine help-seeking behaviour at stroke onset, in order to understand delays in accessing acute medical care for stroke symptoms.

Methods 149 consecutive patients hospitalised with ischaemic stroke were interviewed at $72 \mathrm{~h}$ poststroke with the Stroke Awareness Questionnaire and the Response to Symptoms Questionnaire.

Results Sixty per cent of stroke cases presented to the ED within $3.5 \mathrm{~h}$ of stroke onset. Knowledge of stroke symptoms and risk factors was poor, with $40 \%$ unable to correctly define a stroke. Bystander recognition of symptoms $(p=0.03)$ and bystander initiation of Emergency Medical Services was associated with ED presentation within $3.5 \mathrm{~h}$ ( $p=0.03$ ).

Conclusions This study provides insights into patient response when a stroke occurs, with the presence and action of others highlighted as critical in fast response to stroke symptoms. Knowledge of stroke warning signs and risk factors was low among stroke survivors. Findings highlight the complexity of changing helpseeking behaviour during stroke onset, and provide directions for public education efforts to reduce prehospital delay.

\section{INTRODUCTION}

Delayed hospital arrival has been identified as the most significant prehospital barrier to thrombolysis within $4.5 \mathrm{~h}$ for acute ischaemic stroke. ${ }^{1}$ Given the time-limiting nature of thrombolysis treatment, ${ }^{2}$ onset-to-door (OTD) time is a critical concept in acute stroke treatment that may be examined to identify where patient delays in accessing suitable treatment may occur. Public educational campaigns for stroke awareness aim to increase stroke victim and bystander recognition of stroke symptoms and promote the need for emergency response, with the ultimate goal of improved patient response times, faster transportation to hospital and improved access to thrombolysis. To date, campaigns of this type have demonstrated efficacy for improving population stroke knowledge, ${ }^{3}$ however the association between stroke knowledge and improved OTD time is poor, ${ }^{45}$ with evidence from a systematic review $^{6}$ and time-series studies ${ }^{7} 8$ reporting that the impact of mass media campaigns

\section{Key messages}

What is already known on this subject? Thrombolysis therapy is underused in ischaemic stroke with patient delay in presenting to hospital identified as the leading barrier to thrombolysis administration. Little is known about the role of social, cognitive and emotional factors in help-seeking behaviour when stroke symptoms occur.

\section{What might this study add?} Interviews with 149 patients with stroke at two hospitals in Dublin found that stroke knowledge was poor and the need for urgent action at the onset of symptoms was not appreciated. Those who developed symptoms with a bystander present were more likely to arrive at the hospital within the appropriate treatment window. Based on our findings, we suggest that the focus of future stroke education is to further improve the public stroke knowledge and recognition through improved stroke education strategies.

on help-seeking behaviour during stroke onset is limited.

Guidelines suggest that social, cognitive and emotional factors must be included in comprehensive analysis of delayed help-seeking behaviour in acute stroke, ${ }^{9}$ however studies to date have largely focused on demographic and clinical predictors, with no common consensus on which factors contribute to prehospital delay. ${ }^{10-12}$ Given the growing number of public awareness campaigns for stroke, the challenge remains in identifying factors that bring about impactful changes to behaviour when symptoms occur. ${ }^{13}$ The aim of this study was to examine knowledge of stroke warning signs and risk factors and help-seeking behaviour when stroke symptoms occurred in a cohort of stroke survivors. A secondary aim of this study was to examine the association between patient characteristics, stroke awareness and OTD time when stroke symptoms occurred.

\section{METHODS}

\section{Study design}

A cross-sectional design was employed to examine help-seeking behaviour when stroke symptoms occurred within a consecutive sample of patients hospitalised with acute stroke recruited from two 
large teaching hospitals in North Dublin. The hospital sites have been described in detail in a previous study. ${ }^{8}$ In brief, hospital A serves a catchment area of approximately 290000 , provides a routine 24/7 thrombolysis service and has an acute stroke unit. It is the National Referral Centre for Neurology and Neurosurgery. Hospital B serves a population of approximately 331000 , and provides an 08:00-17:00 thrombolysis service, with out-of-hours potential thrombolysis cases transferred (or rerouted if via Emergency Medical Services (EMS)) to another hospital in North Dublin with a 24/7 thrombolysis service. It also has an acute stroke unit. The standard protocol for thrombolysis administration in both hospital sites required initiation of intravenous thrombolysis administration not later than $4.5 \mathrm{~h}$ after first symptom onset. Ethical approval was granted from the research ethics committees of the participating hospitals. The FAST (Face, Arm, Speech, Time) media message is an internationally used public stroke education message, and since May 2010 has been in national circulation in Ireland, both as an initial intense television and radio mass media campaign (20102011) and subsequently in other formats, such as print media, during the study period. ${ }^{14}$

Data were collected as part of a larger prospective study, the Action on Secondary Prevention Interventions and Rehabilitation in Stroke (ASPIRE-S) Study ${ }^{15}{ }^{16}$ which assessed patients with stroke and their carers at 6 months poststroke. The aim of the ASPIRE-S study was to profile secondary preventive strategies and delivery of rehabilitative need after an ischaemic stroke. Study recruitment took place from 1 October 2011 to 31 September 2012 due to the research funding, and this recruitment period determined the sample size, rather than statistical considerations.

\section{Recruitment procedure and exclusion criteria}

The case ascertainment procedure involved daily contact with a senior member of the medical team on call with responsibility for stroke. Potential cases were identified through consultation with the team following confirmation of stroke on CT or MRI brain imaging. All demographic and clinical information was extracted from the participant's hospital chart during the recruitment process. All hospitalised stroke cases where stroke occurred outside of the hospital were eligible for study inclusion. Patients were excluded from recruitment to the study if they met the following exclusion criteria: stroke diagnosed as subarachnoid haemorrhage; intracerebral haemorrhage or subdural and extradural haematoma; inhospital onset of stroke symptoms; transient ischaemic attack (TIA), inability to complete study interview.

\section{Measures}

Prestroke functional dependency was assessed retrospectively and at $72 \mathrm{~h}$, using the Modified Rankin Scale (mRS), ${ }^{17}$ a commonly used measure of global disability used as a functional outcome measure in stroke populations. ${ }^{18}$ Scores can range from 0 (no symptoms) to 6 (deceased). All participants completed a semistructured interview which included the following measures.

\section{Stroke Awareness Questionnaire}

The Stroke Awareness Questionnaire ${ }^{19}$ was employed to assess knowledge of stroke symptoms and risk factors for stroke. The development of this tool has been previously described. ${ }^{19}$ When used previously with the general population, adequate stroke knowledge was defined as naming $\geq 2$ stroke symptoms.
Response to Symptoms Questionnaire

Patients hospitalised with stroke completed the Response to Symptoms Questionnaire (RSQ), which is an instrument designed to obtain information about patient delay during symptom onset. The RSQ was originally developed for the study of patient delay in myocardial infarction, ${ }^{20}$ thus the wording of the instrument was modified for use in ischaemic stroke. The RSQ explores six domains: (1) context of symptom involvement, (2) antecedents of symptoms, (3) emotional response to symptoms, (4) behavioural response to symptoms, (5) cognitive response to symptoms and (6) response of others to symptoms. Content validity for the instrument has been previously reported as adequate. ${ }^{21} 22$ Additional questions were added to examine participant knowledge of the FAST campaign and if they remembered the FAST campaign when stroke symptoms occurred. After an initial pilot of the extended version no further changes to the RSQ were made. Intermittent television, print and social media advertising of the FAST message was in operation at the time of study recruitment. Items with a low response rate $(<5 \%)$ were not reported in this analysis.

\section{Statistical analysis}

Descriptive statistics and non-parametric comparisons using $\chi^{2}$ test and Fisher's exact test for categorical variables and Kruskal-Wallis test for continuous variables were used to examine the association between patient characteristics and OTD time. Recommendations state that a maximum of $60 \mathrm{~min}$ should be given for time from hospital arrival to initiation of thrombolysis treatment, with this hour incorporating inhospital diagnostic tasks for thrombolysis eligibility assessment, including stroke physician assessment and CT imaging. ${ }^{23}$ An OTD time of $\leq 3.5 \mathrm{~h}$ allows appropriate inhospital processing for timely thrombolysis administration thus the time cut-off of $>3.5 \mathrm{~h}$ was chosen as the definition of prehospital delay for the purposes of this analysis.

\section{RESULTS}

\section{Sample characteristics}

During the study period, 396 cases from the participating hospital sites were referred as potential study participants. Of these, 188 participants were consecutively recruited to the study as meeting the study inclusion criteria (figure 1). Approximately $52 \%$ of all referred cases were ineligible for study inclusion, with the most common reasons for non-inclusion recorded as: patient diagnosed as TIA following MRI (17.9\%); too medically unwell $(16 \%)$. Of the 188 cases recruited to the study, 149 (79\%) completed an interview using the modified RSQ. Demographic characteristics are outlined in table 1. Overall, mean age was 69.3 years $( \pm 13.05)$, with males representing $60 \%$ of the sample. Median OTD time for the sample was $123 \mathrm{~min}$ (IQR 67-472). mRS scores were categorised into $\leq 3$ or $>3$ in order to categorise stroke cases into mild versus moderate to severe stroke. Based on this classification, mRS scores at $72 \mathrm{~h}$ indicated that $42.5 \%$ of the sample were classified as having a moderate to severe stroke.

\section{Delay to ED presentation}

OTD time was recorded in minutes at point of data collection and truncated at $24 \mathrm{~h}(1440 \mathrm{~min})$ as onset times after this cut-off point were found to be poorly reported and difficult to quantify. OTD time data were reported for $69.7 \%(\mathrm{~N}=131)$. Wake-up stroke accounted for $8.5 \%(\mathrm{~N}=16)$ of the sample, and a further $8 \%(\mathrm{~N}=15)$ had an unknown time of onset. OTD times for $13.8 \%(\mathrm{~N}=26)$ exceeded $24 \mathrm{~h}$. Of the sample with a 
Figure 1 Flow chart of recruitment. TIA, transient ischaemic attack.

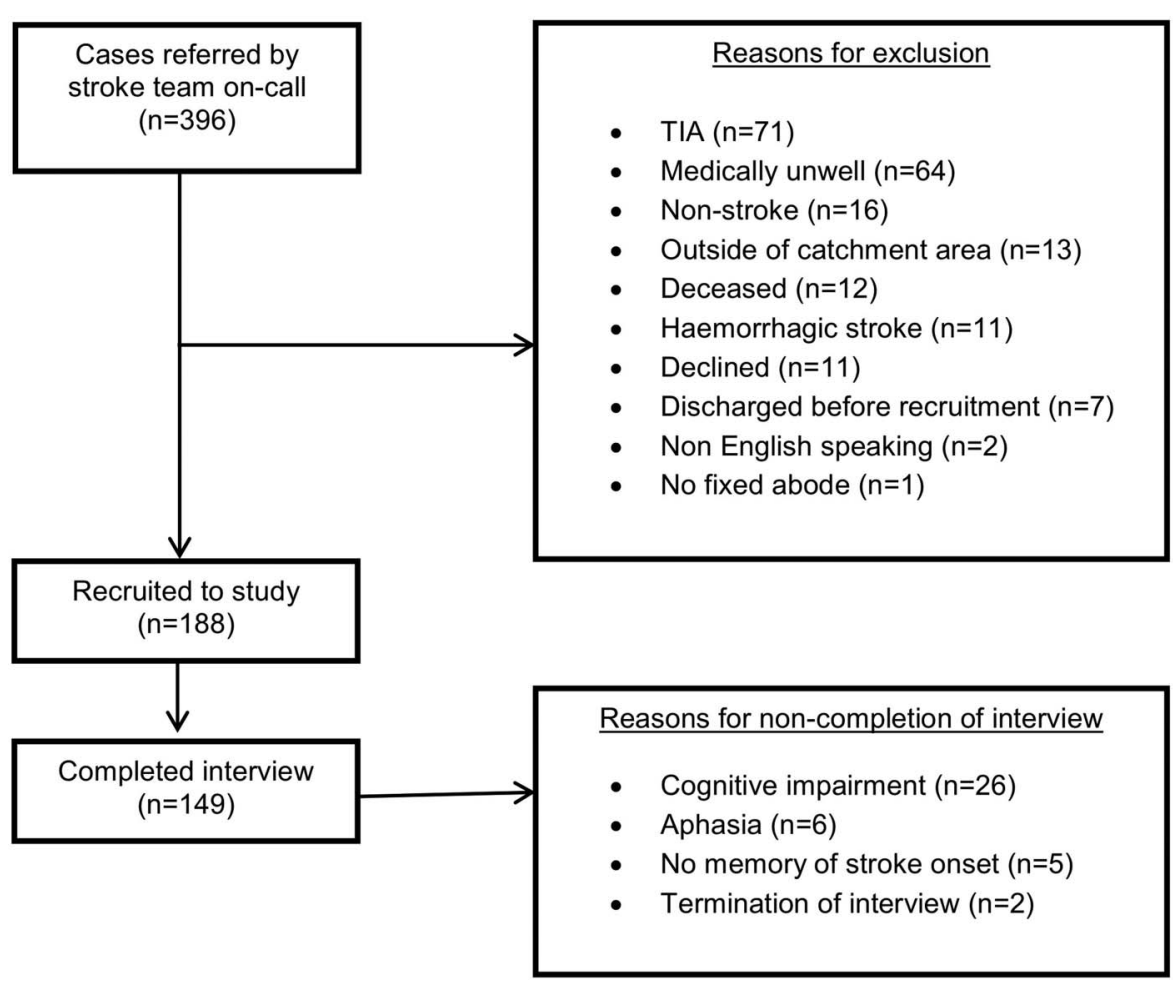

recorded OTD time, $60.3 \%(\mathrm{~N}=79)$ arrived at the ED within $3.5 \mathrm{~h}$. Table 1 outlines the baseline demographic and clinical details for the sample by OTD time.

\section{Knowledge of stroke warning signs and risk factors}

Table 2 outlines participant's knowledge of stroke warning signs and risk factors after experiencing an ischaemic stroke. Knowledge of what constitutes a stroke was poor, with $40 \%$ of the sample unable to correctly define a stroke. Of the sample, only $19 \%$ could correctly identify a TIA as a small or mini stroke. There was no statistical difference in OTD time between those who could correctly define a stroke and those unable to define a stroke (60\% vs $40 \%, \mathrm{p}=0.51)$.

Stroke knowledge was identified as suboptimal among the sample, with $35 \%$ unable to name any stroke warning signs. The most commonly identified warning sign was speech

Table 1 Demographic and clinical characteristics of the sample during hospital admission with ischaemic stroke by OTD time

\begin{tabular}{|c|c|c|c|c|}
\hline Variable & $\begin{array}{l}\text { Overall sample } \\
\mathrm{N}=149\end{array}$ & $\begin{array}{l}\text { OTD time } \leq 3.5 \mathrm{~h}(\mathrm{~N}=79) \\
\mathrm{N}(\%)\end{array}$ & $\begin{array}{l}\text { OTD time }>3.5 \mathrm{~h}(\mathrm{~N}=52) \\
\mathrm{N}(\%)\end{array}$ & $\mathrm{p}$ Value \\
\hline Age & Mean $69.3(S D \pm 13.05)$ & Mean $68.6(S D \pm 11.6)$ & Mean $71.1(S D \pm 13.5)$ & 0.17 \\
\hline Gender (male) & $88(59)$ & $50(63.3)$ & $29(36.7)$ & 0.39 \\
\hline Distance from hospital (km) & Mean $12.6(S D \pm 15.8)$ & Mean $10.2(S D \pm 12.9)$ & Mean $12.2(S D \pm 16.7)$ & 0.98 \\
\hline Consent & & & & 0.27 \\
\hline Self-consent & $136(91.2)$ & $72(91)$ & $50(96)$ & \\
\hline Proxy-consent & $13(9)$ & $7(9)$ & $2(4)$ & \\
\hline Marital status & & & & 0.59 \\
\hline Married & $97(65.1)$ & 55 (70) & $31(60)$ & \\
\hline Single & $13(9)$ & $6(8)$ & $6(12)$ & \\
\hline Other & $39(26.2)$ & $18(23)$ & $15(29)$ & \\
\hline Living arrangements & & & & 0.73 \\
\hline Alone & $36(24.2)$ & $16(20)$ & $13(25)$ & \\
\hline With others & $113(75.8)$ & $63(80)$ & $39(75)$ & \\
\hline Admitted from & & & & 0.14 \\
\hline Home & $119(80)$ & $63(80)$ & $46(88)$ & \\
\hline History of previous stroke/TIA & $32(21.5)$ & $17(22)$ & $12(23)$ & 0.83 \\
\hline Length of stay (days) & Mean $36.8(S D \pm 16.5)$ & Mean $33.2(S D \pm 49.5)$ & Mean $34.2(S D \pm 44.9)$ & 0.28 \\
\hline Received thrombolysis treatment with tissue-plasminogen activator & $16(10.7)$ & $19(24)$ & $1(2)$ & $0.00^{*}$ \\
\hline Was admitted to stroke unit & $99(66.4)$ & $55(70)$ & $33(63)$ & 0.65 \\
\hline $\mathrm{mRS}$ at $72 \mathrm{~h}$ poststroke & $2.18( \pm 1.51)$ & Mean $2.05(S D \pm 1.61)$ & Mean $2.04(S D \pm 1.41)$ & 0.92 \\
\hline OTD time in minutes $(\mathrm{N}=131)$ & Median 123 (IQR 67-472) & Median 72 (IQR 60-107) & Median 614 (IQR 329-918) & $<0.001$ \\
\hline
\end{tabular}


Table 2 Stroke knowledge at time of stroke onset

\begin{tabular}{|c|c|c|c|c|c|c|c|c|}
\hline & $\begin{array}{l}\text { Overall sample } \\
\text { ( } N=149)\end{array}$ & $\%(95 \% \mathrm{Cl})$ & $\begin{array}{l}\text { OTD time } \\
\leq 3.5 \mathrm{~h}(\mathrm{~N}=79) \\
\mathrm{N}\end{array}$ & $\%(95 \% \mathrm{Cl})$ & $\begin{array}{l}\text { OTD time } \\
>3.5 \mathrm{~h}(\mathrm{~N}=52) \\
\mathrm{N}\end{array}$ & $\%(95 \% \mathrm{Cl})$ & $p$ Value & $\begin{array}{l}\text { Missing data } \\
\mathrm{N}(\%)\end{array}$ \\
\hline Stroke definition & & & & & & & & $9(6)$ \\
\hline Blood clot to the brain & 53 & 37 (29 to 45$)$ & 28 & 35 (25 to 47$)$ & 15 & 29 (17 to 43$)$ & 0.51 & \\
\hline Brain haemorrhage & 2 & $1.4(0$ to 6$)$ & 0 & $0(0$ to 0$)$ & 2 & $4(0$ to 13$)$ & & \\
\hline A condition affecting the brain & 25 & 17.5 (12 to 25$)$ & 7 & $9(4$ to 17$)$ & 13 & 25 (14 to 39$)$ & & \\
\hline Circulation problem in the brain & 5 & 3.5 (1 to 8$)$ & 2 & $3(0$ to 8$)$ & 1 & $2(0$ to 13$)$ & & \\
\hline Do not know & 55 & 39.9 (31 to 47$)$ & 16 & 20 (12 to 31$)$ & 25 & 48 (34 to 62$)$ & & \\
\hline Symptoms identified & & & & & & & & $8(5)$ \\
\hline Unilateral weakness & 51 & 36.1 (29 to 45$)$ & 30 & 38 (27 to 50$)$ & 15 & 29 (17 to 43$)$ & 0.32 & \\
\hline Speech disturbance & 46 & 32.6 (25 to 41$)$ & 24 & 30 (21 to 42$)$ & 12 & 29 (17 to 43$)$ & 0.4 & \\
\hline Facial droop & 39 & 27.6 (21 to 36$)$ & 22 & 28 (18 to 39$)$ & 10 & 20 (10 to 33$)$ & 0.29 & \\
\hline Dizziness & 8 & 5.7 (3 to 11$)$ & 2 & $3(0$ to 8$)$ & 3 & 6 (1 to 16$)$ & 0.32 & \\
\hline Named FAST campaign & 13 & 9.2 (5 to 15$)$ & 8 & $10(0$ to 19$)$ & 4 & $8(2$ to 19$)$ & 0.68 & \\
\hline Visual problems & 7 & $5(2$ to 10$)$ & 3 & $4(0$ to 11$)$ & 3 & $6(1$ to 16$)$ & 0.57 & \\
\hline Confusion & 6 & $4.3(2$ to 9$)$ & 2 & $3(0$ to 8$)$ & 3 & $6(1$ to 16$)$ & 0.32 & \\
\hline Headache & 6 & 4.3 (2 to 10$)$ & 2 & $3(0$ to 8$)$ & 2 & $4(0$ to 13$)$ & 0.64 & \\
\hline Numbness & 6 & 4.3 (2 to 9$)$ & 4 & $5(1$ to 12$)$ & 1 & 2 (0 to 13$)$ & 0.38 & \\
\hline Risk factors identified & & & & & & & & $8(5)$ \\
\hline Smoking & 41 & 29 (22 to 37 ) & 19 & 24 (15 to 35$)$ & 11 & 21 (11 to 35$)$ & 0.77 & \\
\hline Stress & 29 & 20.6 (15 to 28$)$ & 12 & 15 (8 to 25$)$ & 10 & 20 (10 to 33$)$ & 0.48 & \\
\hline Hypertension & 23 & 16.3 (11 to 23$)$ & 9 & 11 (5 to 21 ) & 8 & 15 (7 to 28$)$ & 0.45 & \\
\hline Hypercholesterolaemia & 21 & 14.9 (10 to 22$)$ & 13 & 16 (9 to 26$)$ & 4 & 8 (2 to 19$)$ & 0.16 & \\
\hline Alcohol consumption & 18 & 12.8 (8 to 19$)$ & 7 & 9 (4 to 17$)$ & 5 & 10 (3 to 21$)$ & 0.83 & \\
\hline Lack of exercise & 16 & 11.4 (7 to 18$)$ & 9 & 11 (5 to 21$)$ & 5 & 10 (3 to 21$)$ & 0.79 & \\
\hline Overweight & 15 & 10.6 (6 to 17$)$ & 6 & 8 (3 to 16$)$ & 5 & 10 (3 to 21$)$ & 0.64 & \\
\hline Poor diet & 9 & 6.3 (3 to 12$)$ & 7 & 9 (4 to 17$)$ & 1 & 2 (0 to 13$)$ & 0.11 & \\
\hline Older age & 4 & $2.8(1$ to 7$)$ & 2 & $3(0$ to 8$)$ & 1 & $2(0$ to 13$)$ & 0.84 & \\
\hline Diabetes & 3 & 2 (0 to 6$)$ & 2 & $3(0$ to 8$)$ & 0 & 0 (0 to 0$)$ & 0.26 & \\
\hline Able to identify $\geq 2$ stroke warning signs & & 36.7 (29 to 45$)$ & 25 & $32(22$ to 43$)$ & 17 & 33 (20 to 47$)$ & 0.88 & $8(5)$ \\
\hline Able to identify $\geq 2$ stroke risk factors & & 40.4 (33 to 49$)$ & 29 & 37 (26 to 48$)$ & 16 & 31 (19 to 45$)$ & 0.55 & $8(5)$ \\
\hline Primary source of information about stroke & & & & & & & & $8(5)$ \\
\hline Television & 30 & 21 (15 to 29 ) & 16 & 20 (12 to 31$)$ & 10 & 20 (10 to 33$)$ & 0.56 & \\
\hline Radio & 1 & 0.7 (0 to 5$)$ & 0 & $0(0$ to 0$)$ & 1 & $2(0$ to 13$)$ & & \\
\hline Family & 16 & 11.3 (7 to 18$)$ & 10 & 13 (6 to 22$)$ & 2 & $4(0$ to 13$)$ & & \\
\hline Friends & 4 & $2.8(1$ to 7$)$ & 3 & $4(0$ to 11$)$ & 1 & $2(0$ to 13$)$ & & \\
\hline General knowledge & 18 & $12.8(8$ to 19$)$ & 5 & $6(2$ to 14$)$ & 7 & 13 (6 to 26$)$ & & \\
\hline GP & 9 & 6.3 (3 to 12$)$ & 4 & $5(1$ to 12$)$ & 3 & 6 (1 to 16$)$ & & \\
\hline Hospital doctor & 8 & 5.7 (3 to 11$)$ & 5 & $6(2$ to 14$)$ & 2 & $4(0$ to 13$)$ & & \\
\hline Do not know anything about stroke & 52 & 36.8 (29 to 45$)$ & 22 & 28 (18 to 39$)$ & 15 & 29 (17 to 43$)$ & & \\
\hline Perception of seriousness of symptoms & & & & & & & & $26(17)$ \\
\hline Extremely serious and life-threatening & 12 & 8 (5 to 14$)$ & 9 & 11 (5 to 21$)$ & 2 & $4(0$ to 13$)$ & 0.007 & \\
\hline Very serious & 31 & 20.8 (15 to 28$)$ & 17 & 22 (13 to 32 ) & 9 & 17 (8 to 30$)$ & & \\
\hline Moderately serious & 33 & 22.2 (16 to 30$)$ & 21 & 27 (17 to 38$)$ & 6 & 12 (4 to 23 ) & & \\
\hline Mildly serious & 22 & $14.8(10$ to 21$)$ & 4 & $5(1$ to 12$)$ & 10 & 20 (10 to 33$)$ & & \\
\hline Not at all serious & 25 & $16.8(12$ to 24$)$ & 8 & 10 (4 to 19$)$ & 11 & 21 (11 to 35$)$ & & \\
\hline Perception of stroke risk & & & & & & & & $19(13)$ \\
\hline Very high risk & 27 & 18 (13 to 25$)$ & 11 & 14 (7 to 24$)$ & 7 & 13 (6 to 26$)$ & 0.44 & \\
\hline High risk & 1 & 0.7 (0 to 5$)$ & 1 & $1(0$ to 7$)$ & 0 & $0(0$ to 0$)$ & & \\
\hline Moderate risk & 9 & 6 (3 to 11$)$ & 14 & 18 (10 to 28$)$ & 8 & 15 (7 to 28$)$ & & \\
\hline Mild risk & 25 & 16.7 (12 to 24$)$ & 28 & 35 (25 to 47$)$ & 23 & 44 (30 to 59$)$ & & \\
\hline Not at risk & 68 & 45.6 (38 to 54$)$ & 11 & 14 (7 to 24$)$ & 2 & $4(0$ to 13$)$ & & \\
\hline
\end{tabular}

Participants could name more than one stroke symptoms or stroke risk factors.

FAST, Face, Arm, Speech, Time; GP, general practitioner; OTD, onset-to-door.

disturbance (32.6\%). Using the standard cut-off for stroke knowledge (ability to $\geq 2$ warning signs ${ }^{16}$ ), 36.7\% $(\mathrm{N}=51)$ had adequate stroke knowledge for stroke warning signs. There was no statistical difference in OTD time between those who could name $\geq 2$ stroke symptoms and those who named $<2$ stroke symptoms ( $32 \%$ vs $33 \%, p=0.88)$. Interestingly, $48 \%$ were unable to name any stroke risk factors, with smoking the most commonly identified risk factor (29\%). Using the standard 
cut-off (ability to name $\geq 2$ risk factors $\left.{ }^{16}\right), 40.4 \%(\mathrm{~N}=57)$ had adequate knowledge for stroke risk factors. There was no statistical difference in OTD time between those who could name $\geq 2$ stroke risk factors and those who named $<2$ stroke risk factors (44\% vs $38 \%, \mathrm{p}=0.55)$.

\section{Response to stroke symptoms}

Eighty-eight per cent of patients reported that stroke onset occurred at home, and 65\% were in the presence of others when they noticed the occurrence of symptoms (table 3). Only 15.3\% identified the problem as a stroke when symptoms first occurred. Participants were also asked to rate their perceived stroke risk prior to the stroke event itself, with almost half of the sample (45.6\%) stating that they did not think they were at risk at all (table 3).

Table 3 outlines patient responses when stroke occurred. In $44 \%$ of the sample, it was another individual who first noticed stroke symptoms, and a higher proportion of patients with stroke presented to the ED within the thrombolysis window if symptoms were first noticed by someone other than the patient $(51 \%$ vs $31 \%, \mathrm{p}=0.03)$, and if the bystander called for an ambulance $(35 \%$ vs $17 \%, \mathrm{p}=0.03$ ). Interestingly, the emotional reaction of the bystander was also important for faster response. A higher proportion of patients presented to the ED within the thrombolytic window if they reported that the bystander got upset when symptoms occurred $(19 \%$ vs $0 \%, \mathrm{p}=0.008)$. Twenty-three per cent reported that they decided to rest when symptoms occurred. This behaviour was associated with delayed ED arrival, with only $8 \%$ of those arriving $<3.5$ h resting when symptoms occurred, as compared with $25 \%$ of those who arrived outside of the thrombolytic window $(p=0.006)$.

Participants were asked if they had seen or heard any advertisements in relation to stroke prior to the event, of which $75 \%$ of the sample could accurately describe the FAST campaign. Participants were asked if the advert affected their response when symptoms occurred, with approximately only one-third (36.7\%) reporting that the FAST advert influenced their response. A significantly higher proportion of patients presented to the ED within the thrombolytic window if they reported that the FAST campaign affected their response when symptoms occurred (32\% vs $10 \%, \mathrm{p}=0.002)$.

\section{DISCUSSION}

Accurate decision-making during stroke onset is critical to maximise good patient outcomes, and this descriptive cross-sectional study sought to examine patient help-seeking behaviour during stroke onset. Encouragingly, $60 \%$ of patients with stroke presented to the ED within the thrombolytic window, an increase of 14\% from a previously reported Irish study in 2013 in the same location. ${ }^{8}$ Findings also suggest that bystander response plays a key role in faster response when stroke occurs, with recognition, action and emotional response of the bystander all associated with ED arrival within the thrombolysis window in this analysis. Interestingly, the proportion displaying adequate knowledge of stroke warning signs (37\%) was slightly higher than reported population estimates of $31 \%,{ }^{17}$ however a significant gap in adequate stroke knowledge still remains. The proportion displaying adequate knowledge of stroke risk factors

Table 3 Help-seeking behaviour at time of stroke onset

\begin{tabular}{|c|c|c|c|c|c|c|c|c|}
\hline RSQ item & $\begin{array}{l}\text { Overall sample } \\
(\mathrm{N}=149)\end{array}$ & $\%(95 \% \mathrm{Cl})$ & $\begin{array}{l}\text { OTD time } \\
\leq 3.5 \mathrm{~h}(\mathrm{~N}=79) \\
\mathrm{N}\end{array}$ & $\%(95 \% \mathrm{Cl})$ & $\begin{array}{l}\text { OTD time } \\
>3.5 \mathrm{~h}(\mathrm{~N}=52) \\
\mathrm{N}\end{array}$ & $\%(95 \% \mathrm{CI})$ & $\begin{array}{l}p \\
\text { Value }\end{array}$ & $\begin{array}{l}\text { Missing data } \\
\mathrm{N}(\%)\end{array}$ \\
\hline Context of symptom onset & & & & & & & & $0(0)$ \\
\hline Others were present & 52 & 35 (29 to 43$)$ & 25 & 32 (22 to 43$)$ & 19 & 37 (24 to 51$)$ & 0.58 & \\
\hline Others noticed symptoms first & 66 & 44 (36 to 51$)$ & 40 & 51 (39 to 62) & 16 & 31 (19 to 45$)$ & 0.03 & \\
\hline First action upon noticing symptoms & & & & & & & & $25(17)$ \\
\hline Unable to respond due to symptoms & 31 & 25 (18 to 33 ) & 19 & 24 (15 to 35$)$ & 4 & $8(2$ to 19$)$ & 0.02 & \\
\hline Told someone & 44 & 35 (27 to 44$)$ & 23 & $29(19$ to 40$)$ & 12 & $29(17$ to 43$)$ & 0.34 & \\
\hline Tried to rest & 29 & 23 (17 to 32$)$ & 6 & 8 (3 to 16) & 13 & 25 (14 to 39$)$ & 0.006 & \\
\hline Ignored symptoms & 15 & 12 (7 to 19$)$ & 4 & $5(1$ to 12$)$ & 3 & $6(1$ to 16$)$ & 0.9 & \\
\hline Called an ambulance for myself & & $6(3$ to 11$)$ & 15 & 19 (11 to 29$)$ & 3 & $6(1$ to 16$)$ & 0.15 & \\
\hline Phoned GP & 15 & 12 (7 to 19$)$ & 6 & 8 (3 to 16$)$ & 6 & 12 (4 to 23$)$ & 0.48 & \\
\hline Did not notice symptoms & 30 & 23 (17 to 32$)$ & 16 & 20 (12 to 31$)$ & 7 & 13 (6 to 26$)$ & 0.29 & \\
\hline Thoughts following onset & & & & & & & & $31(21)$ \\
\hline Thought symptoms would go away & 51 & 43 (34 to 52$)$ & 14 & 18 (10 to 28$)$ & 20 & 38 (25 to 53$)$ & 0.007 & \\
\hline Did not think symptoms were serious & 38 & $32(24$ to 41$)$ & 11 & 14 (7 to 24$)$ & 16 & 31 (19 to 45$)$ & 0.02 & \\
\hline How did other people respond? & & & & & & & & $23(15)$ \\
\hline Suggested I rest or take medicine & 14 & 11 (7 to 18$)$ & 4 & $5(1$ to 12$)$ & 4 & $8(2$ to 19$)$ & 0.49 & \\
\hline Suggested I get medical help & 39 & $31(23$ to 40$)$ & 12 & 15 (8 to 25$)$ & 14 & 27 (16 to 41$)$ & 0.06 & \\
\hline Called an ambulance & 38 & $30(23$ to 39$)$ & 28 & 35 (25 to 47$)$ & 9 & 17 (8 to 30$)$ & 0.03 & \\
\hline Drove me to the ED & 13 & 10 (6 to 17$)$ & 6 & 8 (3 to 16$)$ & 5 & 10 (3 to 21$)$ & 0.63 & \\
\hline They got upset & 12 & $10(5$ to 16$)$ & 0 & $0(0$ to 0$)$ & 10 & 20 (10 to 33$)$ & 0.008 & \\
\hline Recall of FAST campaign & & & & & & & & $19(13)$ \\
\hline Remembered advertisements (unprompted) & 42 & $32(25$ to 41$)$ & 44 & 56 (44 to 67$)$ & 27 & 52 (38 to 66$)$ & 0.44 & \\
\hline $\begin{array}{l}\text { Able to describe FAST advertisements } \\
\text { (prompted) }\end{array}$ & 70 & 75 (65 to 83) & 36 & 46 (34 to 57 ) & 20 & 38 (25 to 53$)$ & 0.51 & \\
\hline $\begin{array}{l}\text { Reported that FAST affected response to } \\
\text { symptoms }\end{array}$ & 33 & 37 (27 to 47$)$ & 25 & 32 (22 to 43 ) & 5 & $10(3$ to 21$)$ & 0.002 & \\
\hline
\end{tabular}


was disappointingly low (40\%), lower than estimates of $71 \%$ from the general population, ${ }^{19}$ indicating low knowledge for primary prevention of an ischaemic stroke.

Mass media campaigns often seek to target high-risk groups. However, it is suggested that, given the critical role of bystanders and relatives during stroke onset, education strategies should not be solely targeted at individuals at high risk of stroke, but also at their social environment. Our findings, in addition to previous research, highlight that the interaction with others plays a key role in the decision-making process. ${ }^{24}$ Research provides evidence to further support this point, with an Australian analysis of ambulance calls for stroke symptoms highlighting that only $3 \%$ of patients called an ambulance for themselves ${ }^{25}$ and the majority of patients relied on external consultation with family or friends. ${ }^{25} 26$ The findings of the current study support this assertion, as only $6 \%$ called an ambulance for themselves. The finding that the action of others in calling an ambulance was associated with quicker hospital arrival supports national stroke education efforts to all age groups, not restriction to those at risk of stroke.

To the authors' knowledge, no study has retrospectively examined self-reported recall of public educational campaigns when stroke occurs. Previous qualitative work in the UK reported that the majority of patients did not recall the FAST message when stroke occurred. ${ }^{27}$ The proportion of the sample who remembered FAST message in our Irish cohort was similarly suboptimal, with just 37\% reporting that it affected their response, indicating that there are still additional health promotion gains to be achieved. Encouragingly, remembering the FAST message when stroke occurred was positively associated with ED arrival within the thrombolytic window, suggesting that public educational campaigns may influence help-seeking behaviour during stroke response.

\section{Study limitations}

The sample size and cross-sectional design of this study precluded predictive analysis, due to considerations for modelling sample size to avoid overfitting of the models and subsequent production of biased estimates of effect size. ${ }^{28}$ A larger sample size may be able to identify associations that this study was underpowered to detect. Additionally, this study relied on data that was collected from stroke survivors. Human memory can often be distorted and inaccurate, with the occurrence of confirmatory bias. In addition, memory can be negatively affected by stroke-related cognitive impairment. ${ }^{29}$ Although every effort was taken to ensure that patient interviews occurred as close to the stroke event as possible (approximately $72 \mathrm{~h}$ ), in some cases interviews were conducted a number of days following the stroke event as patients were too unwell at $72 \mathrm{~h}$. This delay may have introduced a recall bias. It is suggested for future research that the identified bystander is also a study participant in order to confirm the sequence of events after stroke onset.

The thrombolysis rate in this sample was $11 \%$, despite $60 \%$ presenting within the potential thrombolytic window. As the focus of this study was prehospital activity, no data were collected regarding the phase from hospital arrival to treatment (door to needle time (DTN) time), therefore it is not known how many participants were excluded from thrombolysis based on the presence of clinical contraindications. However, this data is essential for improving acute stroke treatment, as it has been estimated that up to a quarter of patients may be eligible for thrombolysis if inhospital management systems reduced delays. ${ }^{30}$ Ongoing clinical audit of ED presentations with stroke and documentation of thrombolysis exclusion reasons are suggested as part of routine stroke care in order to comprehensively reduce time from stroke onset to acute treatment.

\section{CONCLUSIONS}

Recognition of a stroke is a vital part of the stroke 'chain of survival'. ${ }^{19}$ Based on our findings, we suggest that the focus of future stroke education is to further improve the public stroke knowledge and recognition through improved stroke education strategies. Multiple interventions at different levels (eg, population, individual, systemic) may be the best strategy for initiating and sustaining effective behaviour change among patients and bystanders alike. The complexity of individual behaviour during stroke onset cannot be underestimated, and the findings presented in this study provide a basis for further exploration of the role of public educational campaigns and understanding of this important issue in acute stroke response.

Acknowledgements We acknowledge Dr Eamon Dolan, Connolly Hospital, Dublin for facilitation of participant recruitment.

Contributors LM designed the data collection tools, collected data, wrote the statistical analysis plan, cleaned and analysed the data and drafted and revised the paper. FD designed the study and data collection tools and drafted and revised the paper. DW designed the study and data collection tools, implemented the ASPIRE-S study in Beaumont Hospital, Dublin Ireland, monitored data collection and revised the paper. LB and PH designed the data collection tools, collected data, cleaned and analysed the data and revised the draft paper. AH designed the study and data collection tools, monitored data collection and drafted and revised the paper.

Funding LM completed this work as part of the HRB PhD Scholars Programme in Health Services Research funded by the HRB in Ireland under grant no PhD/2007/16.

Competing interests None declared.

Ethics approval Beaumont Hospital Research (Medical) Ethics Committee and Connolly Hospital Research Ethics Committee.

Provenance and peer review Not commissioned; externally peer reviewed.

\section{REFERENCES}

1 Kwan J, Hand P, Sandercock P. A systematic review of barriers to delivery of thrombolysis for acute stroke. Age Ageing 2004;33:116-21.

2 Lees KR, Bluhmki E, von Kummer $\mathrm{R}$, et al. Time to treatment with intravenous alteplase and outcome in stroke: an updated pooled analysis of ECASS, ATLANTIS NINDS, and EPITHET trials. Lancet 2010;375:1695-703.

3 Trobbiani K, Freeman $\mathrm{K}$, Arango $\mathrm{M}$, et al. Comparison of stroke warning sign campaigns in Australia, England, and Canada. Int J Stroke 2013;8:28-31.

4 Addo J, Ayis $\mathrm{S}$, Leon J, et al. Delay in presentation after an acute stroke in a multiethnic population in South London: the South London stroke register. J Am Heart Assoc 2012;1:e001685.

5 Reeves MJ. Reducing the delay between stroke onset and hospital arrival: is it an achievable goal? J Am Heart Assoc 2012;1:e002477.

6 Mellon L, Doyle F, Rohde D, et al. Stroke warning campaigns: delivering better patient outcomes? A systematic review. Patient Relat Outcome Meas 2015:6:61-73.

7 Flynn D, Ford GA, Rodgers $\mathrm{H}$, et al. A time series evaluation of the FAST national stroke awareness campaign in England. PLoS ONE 2014;9:e104289.

8 Mellon L, Hickey A, Doyle F, et al. Can a media campaign change health service use in a population with stroke symptoms? Examination of the first Irish stroke awareness campaign. Emerg Med J 2014;31:536-40.

9 Moser DK, Kimble LP, Alberts MJ, et al. Reducing delay in seeking treatment by patients with acute coronary syndrome and stroke: a scientific statement from the American Heart Association Council on Cardiovascular Nursing and Stroke Council. Circulation 2006;114:168-82

10 Fang J, Yan WH, Jiang GX, et al. Time interval between stroke onset and hospital arrival in acute ischemic stroke patients in Shanghai, China. Clin Neurol Neurosurg 2011;113:85-8

11 Jin $\mathrm{H}$, Zhu S, Wei JW, et al. Factors associated with prehospital delays in the presentation of acute stroke in urban China. Stroke 2012;43:362-70.

12 Qureshi Al, Kirmani JF, Sayed MA, et al. Time to hospital arrival, use of thrombolytics, and in-hospital outcomes in ischemic stroke. Neurology 2005;64:2115-20.

13 [No authors listed]. Increasing the power of public awareness campaigns. Lancet Neurol 2015;14:669

14 Irish Heart Foundation. Act F.A.S.T. Dublin: Irish Heart Foundation, 2010. [cited May 2011]. http://www.stroke.ie 


\section{Original article}

15 Mellon L, Brewer L, Hall P, et al. Cognitive impairment six months after ischaemic stroke: a profile from the ASPIRE-S study. BMC Neurol 2015;15:31.

16 Atteih S, Mellon L, Hall P, et al. Implications of stroke for caregiver outcomes: findings from the ASPIRE-S study. Int I Stroke 2015;10:918-23.

17 Rankin J. Cerebral vascular accidents in patients over the age of 60. II. Prognosis. Scott Med J 1957:2:200-15.

18 Quinn TJ, Dawson J, Walters MR, et al. Functional outcome measures in contemporary stroke trials. Int I Stroke 2009:4:200-5.

19 Hickey A, Holly D, McGee $H$, et al. Knowledge of stroke risk factors and warning signs in Ireland: development and application of the Stroke Awareness Questionnaire (SAQ). Int J Stroke 2012;7:298-306.

20 Burnett RE, Blumenthal JA, Mark DB, et al. Distinguishing between early and late responders to symptoms of acute myocardial infarction. Am J Cardiol 1995;75:1019-22.

21 Dracup K, Moser DK, Eisenberg M, et al. Causes of delay in seeking treatment for heart attack symptoms. Soc Sci Med 1995;40:379-92.

22 Fukuoka Y, Dracup K, Rankin SH, et al. Prehospital delay and independent/ interdependent construal of self among Japanese patients with acute myocardial infarction. Soc Sci Med 2005;60:2025-34.
23 Alberts MJ, Latchaw RE, Selman WR, et al. Recommendations for comprehensive stroke centers: a consensus statement from the Brain Attack Coalition. Stroke 2005;36:1597-618.

24 Teuschl Y, Brainin M. Stroke education: discrepancies among factors influencing prehospital delay and stroke knowledge. Int J Stroke 2010;5:187-208.

25 Mosley I, Nicol M, Donnan G, et al. Stroke symptoms and the decision to call for an ambulance. Stroke 2007;38:361-6.

26 Zerwic J, Hwang SY, Tucco L. Interpretation of symptoms and delay in seeking treatment by patients who have had a stroke: exploratory study. Heart Lung 2007;36:25-34.

27 Dombrowski SU, Mackintosh JE, Sniehotta FF, et al. The impact of the UK 'Act FAST' stroke awareness campaign: content analysis of patients, witness and primary care clinicians' perceptions. BMC Public Health 2013;13:915.

28 Babyak MA. What you see may not be what you get: a brief, nontechnical introduction to overfitting in regression-type models. Psychosom Med 2004;66:411-21.

29 Schacter DL. The seven sins of memory: insights from psychology and cognitive neuroscience. Am Psychol 1999;54:182-203.

30 Boode $B$, Welzen V, Franke $C$, et al. Estimating the number of stroke patients eligible for thrombolytic treatment if delay could be avoided. Cerebrovasc Dis 2007:23:294-8 